Copyright (C) 2020 University of Bucharest Printed in Romania. All rights reserved

ISSN print: $1224-5984$

ISSN online: $2248-3942$

\title{
A microscopic study on the intercanalar isthmuses of the maxillary premolars and associated iatrogenic cracks
}

\author{
PAULA PERLEA ${ }^{1}$, SUCIU IOANA ${ }^{1}$, MIHAI CIOCARDEL ${ }^{2}$, RUXANDRA IOANA \\ BARTOK ${ }^{1}$, MONICA VOICULEANU ${ }^{1}$, SANZIANA SCARLATESCU ${ }^{1}$, MIHAELA TANASE ${ }^{1}$, \\ MIHAELA CHIRILA ${ }^{1}$, OANA AMZA ${ }^{1}$, LUCIA DAINA ${ }^{3 *}$, ALEXANDRU ILIESCU ${ }^{4}$ \\ ${ }^{1}$ University of Medicine and Pharmacy "Carol Davila”, Faculty of Dental Medicine, Bucharest, Romania \\ ${ }^{2}$ University of Petroleum and Gases, Ploiesti, Prahova county, Romania \\ ${ }^{3}$ University of Oradea, Faculty of Medicine and Pharmacy, Oradea, Bihor county, Romania \\ ${ }^{4}$ University of Medicine and Pharmacy of Craiova, Dolj county, Romania
}

\begin{abstract}
The purpose of this microscopic investigation, using stereomicroscopy and light transmited microscopy was to evaluate the configuration of the endodontic treated maxillary premolars, making correlations between the presence of the intercanalar isthmuses and also, to identify possible associated fracture lines. We also evaluated the thickness of the tertiary dentinal layer (irritation dentin layer). The study was based on microscopic investigation on thin sections on fragments or separate preparations resulting from 12 premolars that were clinically compromised. The tertiary dentin is deposited in response to irritations and moderate intensity injuries. As the tendency of crack propagation is directed to the areas corresponding to the root canal towards one of the root surfaces (which is the closest) the crackline - almost without exception, is more or less arched, without detecting an eventual crack in a straight line.
\end{abstract}

Keywords Intercanalar isthmuses, fissure, cracks, sealer, tertiary dentin.

To cite this article: PERLEA P, SUCIU I, CIOCARDEL M, BARTOK RI, VOICULEANU M, SCARLATESCU S, TANASE M, CHIRILA M, AMZA O, DAINA L, ILIESCU A. A microscopic study on the intercanalar isthmuses of the maxillary premolars and associated iatrogenic cracks. Rom Biotechnol Lett. 2020; 25(6): 2161-2167. DOI: $10.25083 / \mathrm{rbl} / 25.6 / 2161.2167$ 


\section{Introduction}

In this current study we analyzed the endodontic configuration of the maxillary premolar with isthmuses and associated root cracks given an old clinical concern of the knowledge on endodontic morphology, targeting accurately preparation and sealing of the root canals.

The study was conducted in the Department of Endodontics, Faculty of Dentistry "Carol Davila" Bucuresti. The teeth enrolled in the study developed pathological cracks, and were selected from among the clinic's patients, as well as from other cases reported by fellow practitioners; thus, there were analyzing the root sections performed on segments from a number of 12 upper extracted premolars. As a marker, regarding the evolution of teeth with cracks, is the tertiary irritation dentin.

After dentin primary formed by deposition of dentin continues at a lower speed, even without the intervention of external factors although this rate and amounts of secondary dentin varies considerably from individual to individual. [1] In secondary dentin tubules and are directed slightly different in contrast with primary dentin.

Secondary dentin is formed on the internal aspect of the pulp chamber cavity, but in the pulp chamber of multirooted teeth, it tends to distribute more thickly on the ceiling and on the floor, rather than on the side walls. Reparative dentin (tertiary) is formed by the secondary odontoblasts, as a replacement in response to moderate levels of irritation, such as attrition, abrasion, erosion and trauma, cavities lessions with moderate speed of evolution, or some operative pocedures. Usually, it appears as a dentin storage located on walls immediately underlying the dentinal area that received an injury, which detects a deposit of dentin located under the affected tubules. Reparative dentin is usually formed following a mechanic preparation at a distance up to $1.5 \mathrm{~mm}$ from the pulp, resulting dead tracts.

Tertiary dentin is limited to areas of irritation of the pulp cavity and is microscopically apparent at about one month following the initiate stimulus and is structurally and chemically different from primary and secondary dentin, being deeply atubular, impervious to irritants.

Tertiary dentin is a defensive reaction to an area of injury of moderate intensity. When the stimuli are applied on dentin (caries, attrition) the affected odontoblanstic complexes may die together with the dental bodies involved, this area of dentin being the dead tracts and are extended from the external surface of the dentin towards the pulp. Tubules are empty layout and appear dark when viewed in transmitted light microscopy on polished sections [10]. Basically dead tracts are sealed at the end of the pulp reparation dentin formed machine by the odontoblasts replacement.

Tracking the present pathological phenomena due to iatrogenic root cracks assumed an tempestuous endodontic treatment, injudicious, because as is known $[9,11]$ due to the complex geometry of the endodontic system on groups of teeth, we have decided to follow the pathology of certain categories, respective teeth of the maxillary premolars. Moreover, it was also observed the absence of phenomena occurring on pathological conditions at the level of intercanal isthmuses, considering an older concern of the main authors.

\section{Material and Methods}

The study was based on microscopic investigation both by stereomicroscopy and light microscopy transmitted on thin sections on fragments or separate preparations resulting from 12 premolars that were clinically compromised.

Preextractionally, these premolars evolved within periods between 1 and 4 years with cracks discovered and produced in vivo. We found that all upper premolars had been treated anteriorly, correctly or incorrectly, with or without coronary obturations. Of the total number of premolars studied only five premolars showed intercanalar isthmuses; following this, on the stereo microscopic analysis we considered a more accurate investigation on the crack path and the degree of colors change (obviously related to the pathological phenomena that have occurred in the crack area) in these cases there have been reports of fragments that tended to move after the occurrence of these discontinuities.

Following the stereoscopic investigation, these premolars were divided into three segments, coronary, medium and apical, with great precision. These surfaces section results were obtained with a degree as perfect flatness being investigated preliminary (with a stereo microscope) with attached digital camera for shooting required om micropaleontological research.

In most cases, macroscopic cracks were noticed with naked eye, posextractional, but also while performing maneuvers of sectioning. The obtained sections were embeded in perfect aralditic transparent matrix resin that did not change any aspect of the histological pattern that we appreciated, so that as not to involve changes in the geometry of the crack path.

Subsequently, these matrix resins were detached thoroughly before taking pictures of stereomicroscopy and partially detached before performing thin sections. To follow in detail pathological phenomena in the endodontic space, it was decided to take, as a reference for all premolars the upper midshaft root, cutting here a slice of about $1 \mathrm{~mm}$, performing thin sections of these. The thin section involves thinning this slice up to $30 \mu \mathrm{m}$ and catching them between the blade and blade.

The stereo microscope with which we worked is a Leica DZ Switzerland microscope, with a digital camera attached that allows high-resolution digital photos. Also, with the aid of the stereomicroscope it was noticed the root level at which the cracks ends on each tooth analyzed $[6,7]$. We have also found that the possibility of detaching a smaller fragment from the root area occurs where the end zone of the crack in the apical area is completely on one of the faces. There are cases where fissures are not continuous, or on contrary, ending in the apical region on the hard tissue $[8,12]$.

\section{Results and Discussions}

Following the study of stereo microscopy that occurred on the obtained sections, it was found that, in addition to various technical errors of the endodontic treatment, in all cases, the intercanalar isthmus was not instrumented. There have been registered varying degrees of color penetration of both the crack areas and the undeveloped fragments that tended to detach. 
After endodontic retreatment, the intercanalar isthmus is observed with satisfactory degree of filling with sealer alternating with areas in which the sealer did not penetrate (Figure 10,11), but where the sealer also penetrated into the space crack (Figure 9, 10), probably contributing to the detachment of the smaller fragment. For example, we chose a set of significant microscopy images.

On the analysis of the thin sections made from slices from the coronal and midshaft root portions, it was found in all cases the presence of tertiary reaction dentin (Figure 1), which is a marker of the pathological phenomena related to the infiltration of the endodontic space.

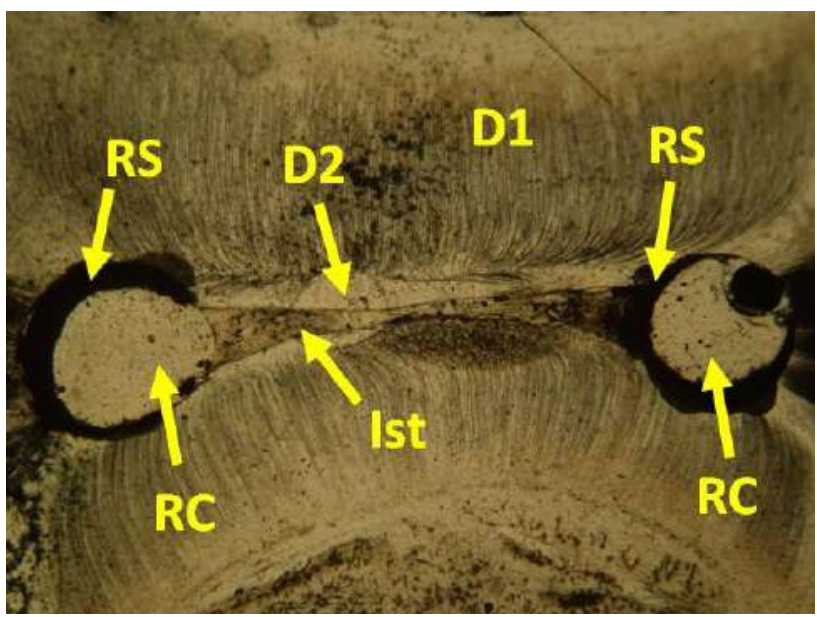

Figure 1. The cross section, which comprises both the obstructed root canals [RC], the sealer [RS], the aspect of the intercanalar isthm with different filling zones [Ist]it also signals the areas of primary dentine [D1] and the presence of tertiary dentine [D2]. magnification X 30
Also, on sections there was also visible sealer remaining on the preparations' walls, near the canals, being imposible to appreciate the tertiary dentin disposal, the latter can be very well seen in the isthmuses their interductal where it is disposed in thick and thin beds, both on the mesial and the distal sides of the isthm (Figure 1).

The deposition of tertiary dentine has narrowed to varying degrees the intercanalar isthmus, which is also dependent on the initial thicknesses of this isthmus. We found that the cross sections in the direction of the isthmuses widen towards the root canals and narrowed somewhere in an area placed somewhat symmetrically between the two channels [V, P]. Given the histological characteristics of tertiary dentin $[4,5]$ and highlighting - in a highly polarized light mode using polarizing filters and compensating devices [special retardation devices] by birefringence different colors, we could appreciate just how far each area of the tertiary dentine section extends, in other words, we have been able to detect the boundary between primary and tertiary dentin.

Using ocular micrometric and calibrations performed on the microscope we operated on, we looked out for each premolar maximum and minimum thickness of the bed. All micrometry was solved on the maximum and minimum widths isthmuses, after the deposit occurred tertiary dentin.

These data together with the crack path, ending at the root level and the microscopic appearance of the crack crack are shown in Table 1.

By macroscopically closed crack - we understand a crack that is macroscopically detectable (the path is visible), but where no space can be perceived between the two domains located on one side and the other.

Table 1. Characteristics of the premolars investigated postexterractically regarding the characteristics of the cracks, the thickness of the tertiary dentine layers and the intercanalar isthmuses

\begin{tabular}{|c|c|c|c|c|c|c|c|c|c|}
\hline \multirow[t]{2}{*}{$\begin{array}{c}\text { Tooth code } \\
\text { microscopically } \\
\text { analyzed }\end{array}$} & \multirow[t]{2}{*}{ Crack path } & \multirow{2}{*}{$\begin{array}{l}\text { The root } \\
\text { level at } \\
\text { which the } \\
\text { crack ends }\end{array}$} & \multirow{2}{*}{$\begin{array}{l}\text { The macroscopic } \\
\text { appearance of the } \\
\text { crack following } \\
\text { immediate } \\
\text { extraction }\end{array}$} & \multicolumn{2}{|c|}{$\begin{array}{l}\text { Thickness of tertiary } \\
\text { dentine blankets to } \\
\text { the mesial }\end{array}$} & \multicolumn{2}{|c|}{$\begin{array}{l}\text { Thickness of tertiary } \\
\text { dentine blankets to the } \\
\text { distal }\end{array}$} & \multicolumn{2}{|c|}{$\begin{array}{l}\text { The width of the isthmus } \\
\text { after the deposition of } \\
\text { tertiary dentine }\end{array}$} \\
\hline & & & & $\begin{array}{l}\max \\
(\mu \mathrm{m})\end{array}$ & $\begin{array}{l}\min \\
(\mu \mathrm{m})\end{array}$ & $\begin{array}{l}\max \\
(\mu \mathrm{m})\end{array}$ & $\begin{array}{l}\min \\
(\mu \mathrm{m})\end{array}$ & $\begin{array}{l}\max \\
(\mu \mathrm{m})\end{array}$ & $\begin{array}{l}\min \\
(\mu \mathrm{m})\end{array}$ \\
\hline PM1 & $\begin{array}{l}\text { From canal V and } \\
\text { canall } P \text { to the } \\
\text { mesial face of the } \\
\text { root }\end{array}$ & 1/3 apical & $\begin{array}{l}\text { Slightly open crack } \\
\text { with the mesial frag- } \\
\text { ment (with detach- } \\
\text { ment tendency) } \\
\text { completely colored } \\
\text { by infiltration }\end{array}$ & 164 & $<84$ & 116 & $<76$ & 220 & 44 \\
\hline PM2 & $\begin{array}{l}\text { V-canal to the } \\
\text { V-face of the root }\end{array}$ & $1 / 3$ average & $\begin{array}{l}\text { Closed crack, infil- } \\
\text { trated look (color } \\
\text { change is noticeable } \\
\text { along the crack) }\end{array}$ & 78 & $<40$ & 60 & $<30$ & 186 & 112 \\
\hline PM3 & $\begin{array}{l}\text { V-canal towards } \\
\text { V-portion of the } \\
\text { root; P-canal to the } \\
\text { M portion of the } \\
\text { root }\end{array}$ & 1/3 apical & $\begin{array}{l}\text { Closed crack, } \\
\text { infiltrated look (color } \\
\text { change is noticeable } \\
\text { along the crack) }\end{array}$ & 88 & $<34$ & 94 & $<48$ & 174 & 64 \\
\hline PM4 & $\begin{array}{l}\text { V-canal towards } \\
\text { the V part of the } \\
\text { root; } \\
\text { P canal to the P } \\
\text { face of the root }\end{array}$ & $\begin{array}{l}\text { The } 1 / 3 \\
\text { midshift-1/3 } \\
\text { apical limit }\end{array}$ & $\begin{array}{l}\text { Closed fissure with a } \\
\text { slightly infiltrated } \\
\text { appearance (the color } \\
\text { change is observed } \\
\text { relatively difficult } \\
\text { along the crack) }\end{array}$ & 66 & $<36$ & 74 & $<38$ & 262 & 180 \\
\hline PM5 & $\begin{array}{l}\mathrm{V} \text { canal and P canal } \\
\text { to the mesial part of } \\
\text { the root }\end{array}$ & $1 / 3$ midshift & $\begin{array}{l}\text { Opened with the } \\
\text { fragment susceptible } \\
\text { to detaching partially } \\
\text { infiltrated }\end{array}$ & 116 & $<60$ & 104 & $<36$ & 244 & 68 \\
\hline
\end{tabular}

Observation: Appreciating the thicknesses of tertiary dentine blankets and the width of the isthmus was done by microscopy on thin sections at a level corresponding to the upper third midshift root. 
On the photo and traversing the compensator $250 \mathrm{X}$ it can be observed maximum tertiary dentin to mesial of $164 \mu \mathrm{m}$ and to distal of $76 \mu \mathrm{m}$. Figures 5 and 6 illustrate a picture in the microscopic image of determining the maximum thickness of the bed of the tertiary dentin towards mesial and distal, respectively on one of the teeth studied and also analysing the thickness of the isthmus, which was the maximum at, or near the canal.

We consider significant in our study that the maximum thickness of tertiary dentine on the two walls given that it was found that the thickness of the tertiary dentin significantly narrows in the direction, almost to extinction, towards the root canals. [14, 15]

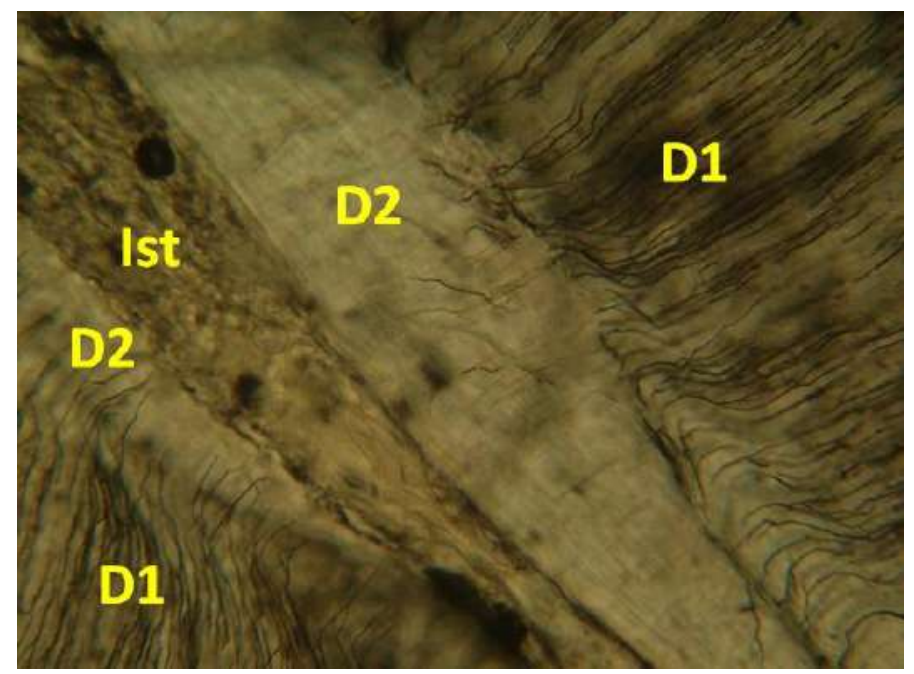

Figure 2. The isthmus appearance, presenting variable widths, flanked by tertiary reaction dentine. Magnification 250x

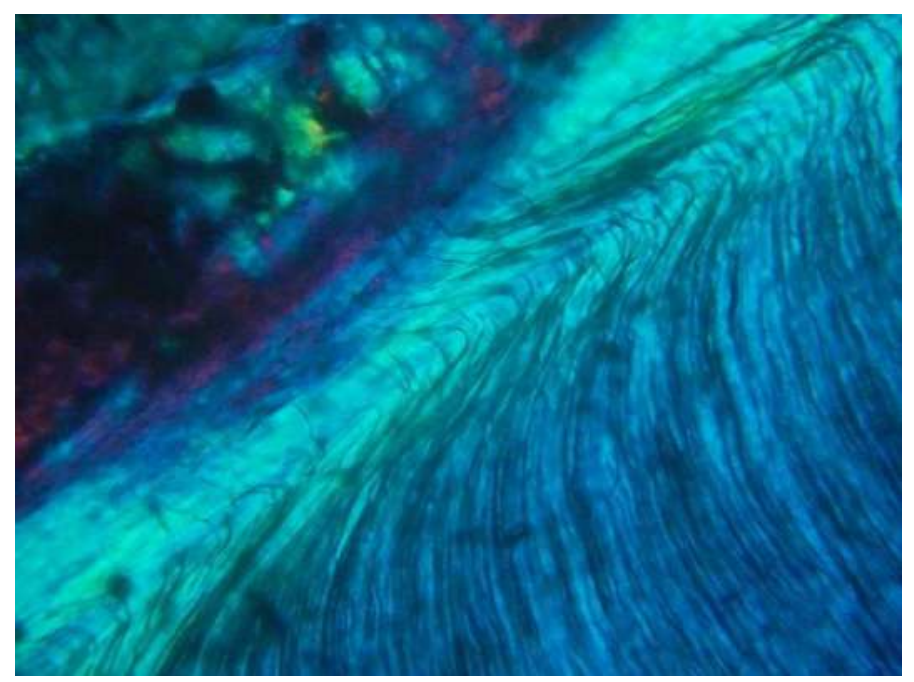

Figure 4. Tertiary dentin, in the vicinity of the isthmus. Magnification $200 \mathrm{X}$
Cracks resulting during tempestuous instrumentation are more likely in incidence $[13,16,17]$ between the root canal space and on mesial part or vestibular parts, as it was the case with the vestibular canal, as well as on the distal part, as it was in the case of the distal canal and when there was the tendency of detachment of a fragment, this fragment, of volume lower than the rest of the remained tooth is bounded by surface cracks, space and intercanalar isthmus.

The geometry of the isthmus at this root level, which we took as a reference to perform our microscopic analysis is illustrated in Figure 2; in this image is observed tertiary dentin [D2], on a very low level, or almost devoid of ducts looking clearer, [D1 ] with clearly visible canals [D1].

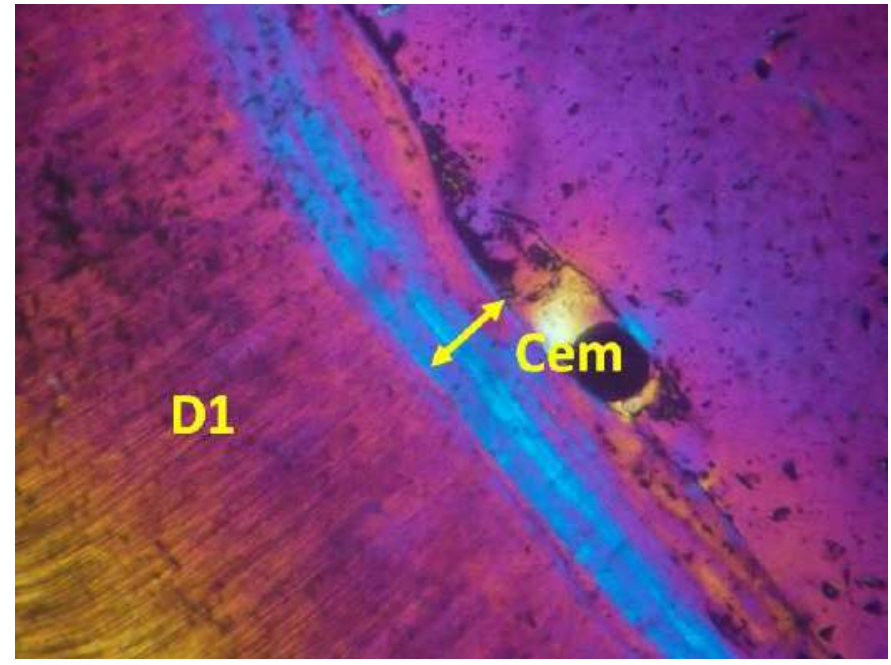

Figure 3. The appearance of primary dentin in the vicinity of the cementum. Magnification $200 \mathrm{X}$

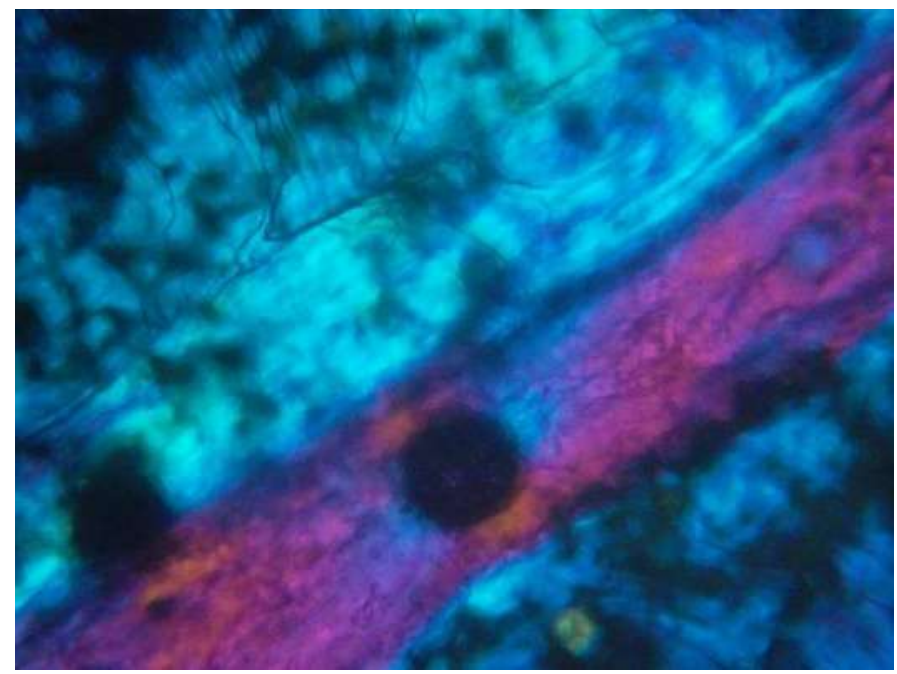

Figure 5. Quasi-constant segment size of the isthmus [65 $\mu \mathrm{m}]$ around which, at the top of the image, is distinguished a layout of tubular tertiary dentin. Magnification 260 X 


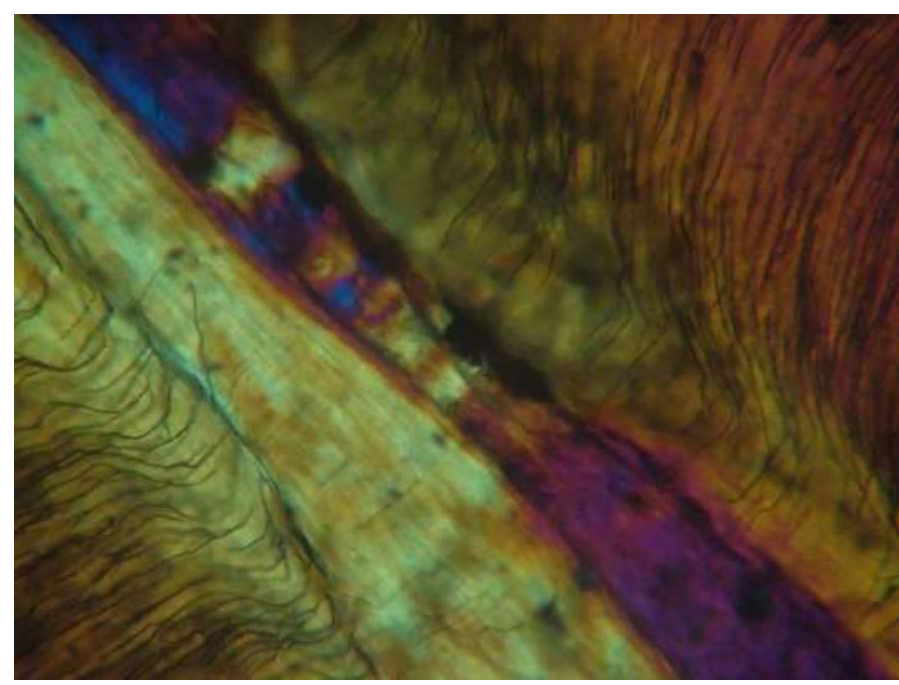

Figure 6. The appearance of the isthmus in the center of the image, with symmetrical increasing trend in the dimensions measured [the top $85 \mu \mathrm{m}$ for lower extremity imaging isthmus measured size increase $-98 \mu \mathrm{m}]$, with the appearance of tertiary dentin, which is observed from the isthmus to the top and bottom of the image and having a highly irregular route]. Magnification of $240 \mathrm{X}$

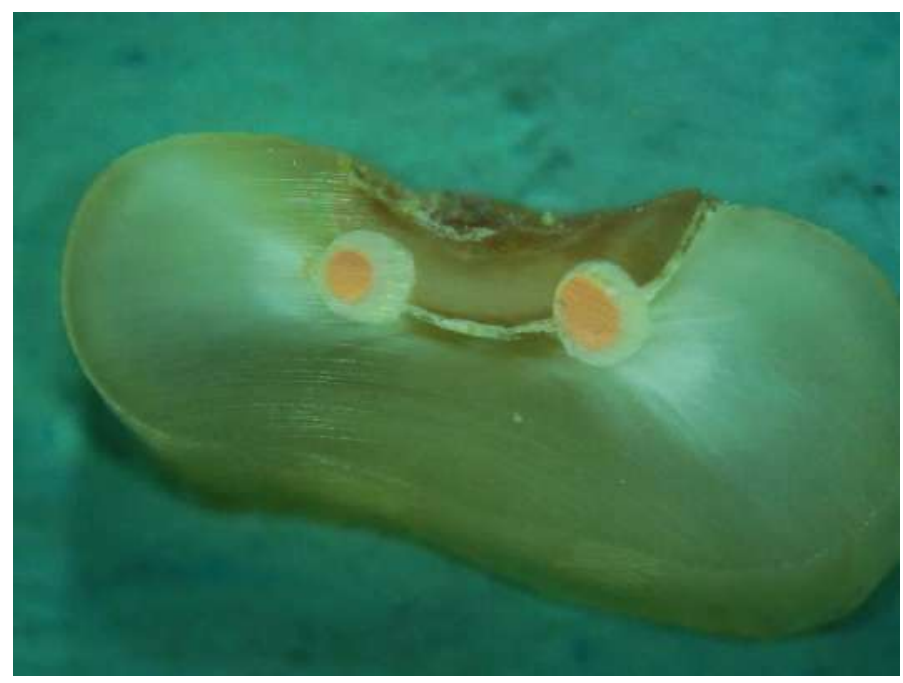

Figure 8. The appearance of the crack which is to come upper- side from the vestibular canal, continuing towards the isthmus, the arcuate path having a substantially delimiting the fractured fragment, which is stronger color- impregnated, being partially filled with sealant. Magnification of 16x

Since the microscopic analysis of thin sections istmusurilor it was developed that locally, the tertiary dentin beds are very wide (Figures 2, 3), we virtually determined the areas that we found the narrow isthmus thickness of beds and tertiary dentin towards the mesial and

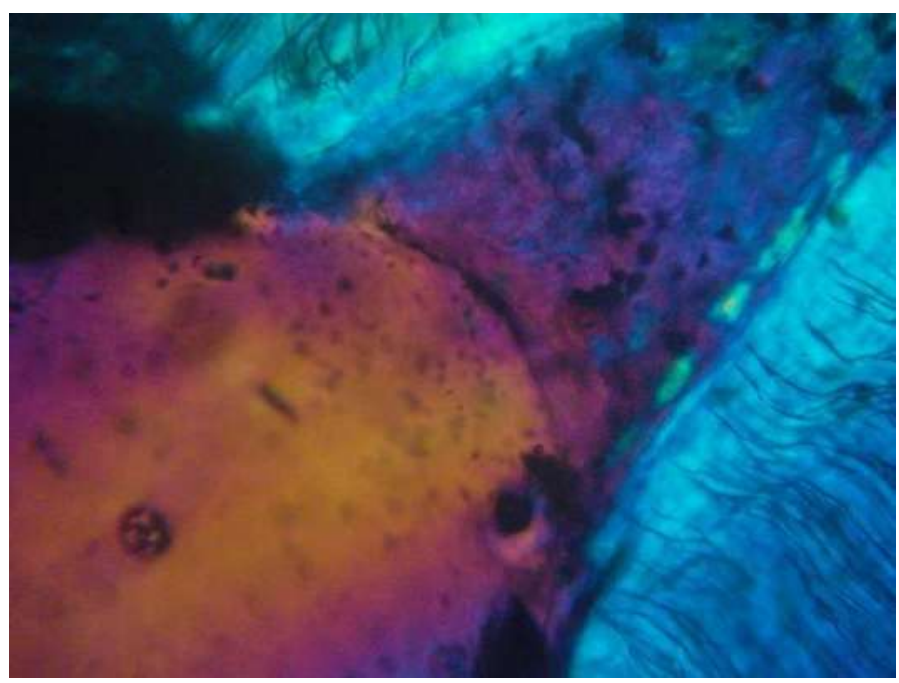

Figure 7. The view of the sealed palatinal canal, with the filtration and outer ducts in the appearance of the image, the isthmus presenting a higher dimension at the interface with the canal, being flanked by beds of tertiary dentin. Magnification of $280 \mathrm{X}$

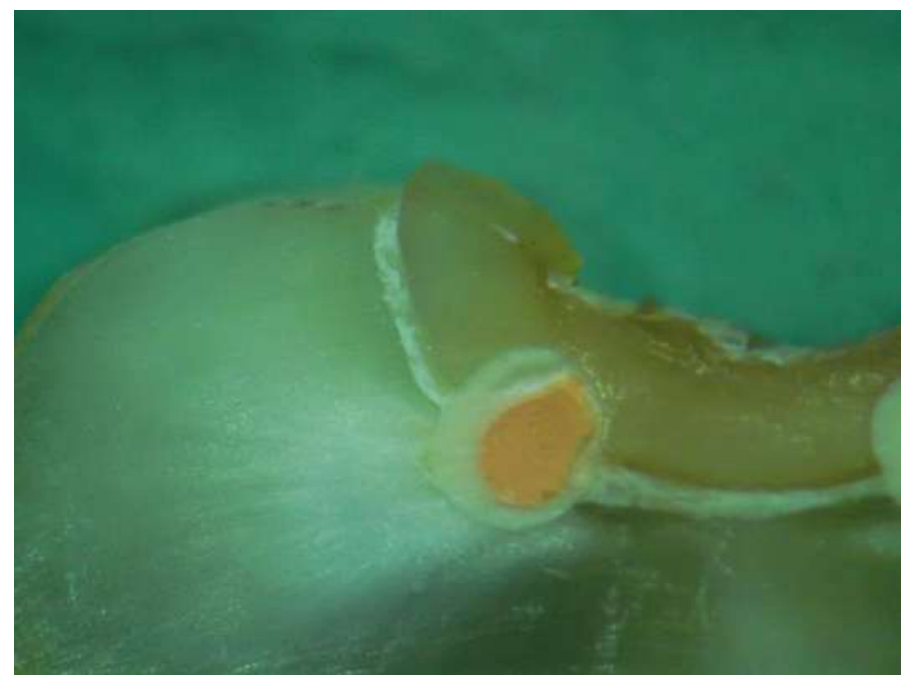

Figure 9. The detailed appearance of a complete fissure, which easily detaches the fragment, whereas they tend to lightly move the fissured fragment, in appearance with discontinuous sealant filling. Magnification of $30 \mathrm{x}$

respectively, distal side and we could appreciate at this level the initial total width of the isthmus, scanning thicknesses of two single tertiary dentin beds and also the degree of narrowing of the isthmus in percentage, given the endodontic pathology; these data are presented in Table 2. 


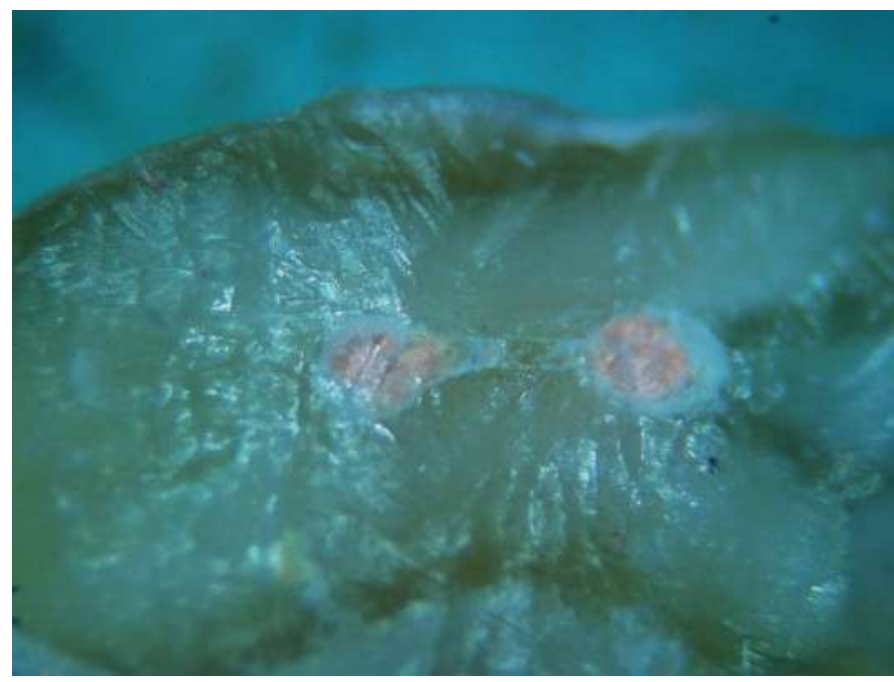

Figure 10. The image of an upper premolar, that captures the medium part with the isthmus that is partially filled with sealant. Magnification of $40 \mathrm{x}$

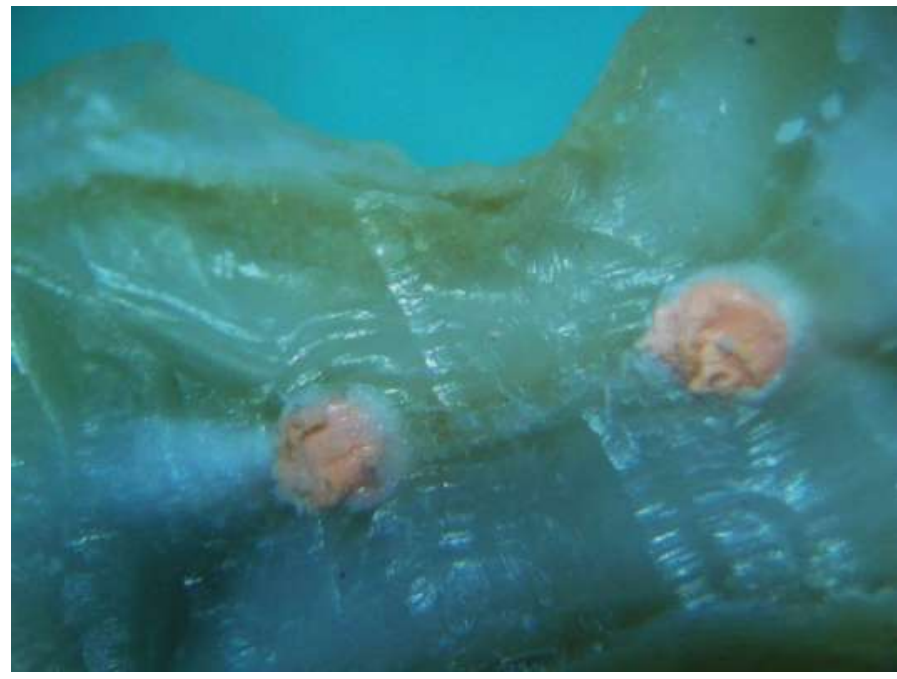

Figure 11. Highlights the crack line that does not cause the fragment to shift to the intercanalar ishmus which is partially filled with sealant. Magnification of $40 \mathrm{X}$

Table 2. Presenting the maximum degree of narrowing of the intercanalicular on premolars through deposition of tertiary dentin

\begin{tabular}{|c|c|c|c|c|c|c|}
\hline $\begin{array}{c}\text { Tooth code } \\
\text { microscopically } \\
\text { analyzed }\end{array}$ & $\begin{array}{l}\text { Minimum } \\
\text { width of the } \\
\text { isthmus } \\
\text { found }\end{array}$ & \begin{tabular}{|} 
The thickness of the \\
tertiary dentine layer to \\
the bifurcation (in the \\
place where the minimal \\
width of the isthmus was \\
identified) \\
$(\mu \mathrm{m})$
\end{tabular} & $\begin{array}{l}\text { The thickness of the } \\
\text { tertiary dentine layer to } \\
\text { the distal (where the } \\
\text { minimum width of the } \\
\text { isthmus was identified) } \\
(\mu \mathrm{m})\end{array}$ & \begin{tabular}{|c|} 
The total thickness \\
of the tertiary \\
dentine (in the \\
place where the \\
minimum width of \\
the isthmus was \\
identified) \\
$(\mu \mathrm{m})$ \\
\end{tabular} & $\begin{array}{c}\text { Initial total } \\
\text { width of the } \\
\text { isthmus } \\
(\mu \mathrm{m})\end{array}$ & $\begin{array}{c}\text { Degree of } \\
\text { isthmus } \\
\text { narrowing } \\
(\%)\end{array}$ \\
\hline PM1 & 44 & 104 & 76 & 180 & 224 & 80.35 \\
\hline PM2 & 112 & 26 & 58 & 126 & 238 & 52.94 \\
\hline PM3 & 64 & 80 & 92 & 172 & 236 & 72.88 \\
\hline PM4 & 180 & 66 & 68 & 134 & 314 & 42.67 \\
\hline $\mathrm{P} \mathrm{m} 5$ & 68 & 108 & 96 & 204 & 272 & 75 \\
\hline
\end{tabular}

Notice: Appreciating the thicknesses of tertiary dentine blankets and the width of the isthmus was done by microscopy on thin sections at a level corresponding to the upper middle third root.

\section{Conclusions}

1) The tertiary dentin is lacking dentinal canals and we consider it to be a marker of endodontic pathology evolution, allowing us to make correlation between the degree of irritation and the tertiary dentin layer depth.

2) Following forced root canal treatment on the internal wall of the root canal can result in cracks which can distribute the towards the outside surfaces of which are nearest to the root canals. On some samples, it was penetrated with the section plane through the crack, thus causing, in some cases, opening them up. The isthmuses could be captured, generally, as narrowed or completely obliterated by deposition of tertiary dentin in the root that we appreciated as a landmark.

3) The degree of narrowing identified by the deposition of tertiary dentin, on apical- coronal way, at the place where we found the narrowest isthmus varies between $42 \%$,
$67 \%$ and $80 \%, 35 \%$. We appreciate the largest narrowing of the isthmus and the thickest layer of tertiary dentin to be noted at the premolars, where the crack was identified as such and / or half- opened and the small fragment with strong likelyhood of detachment.

4) The area in which the tertiary dentin layer is the thickest in the vicinity of the isthmus- and are not necessarily present, but in the circumstance where they are increased- most of them narrowed by depositing the layer of dentin.

5) The thickness of the deposited tertiary dentin does not depend on the location of the isthmus in an apicalcoronary sense, but it depends on the odontoblastic activity and onto the time period of the irritant activity and on the nature of the irritant.

6) Since the isthmuses tapers to the apical part, one would expect it to obliterate the canal faster towards the apical, where available space is notably on smaller deposit. 
7) Obviously these data require further investigations with thin serial sections at different root levels, in order to bring clarification regarding this fact, but this study has not taken this into account.

8) As long as the tendency of spreading the cracks is directed towards the area of the root canal to one of the root surfaces, which is the nearest, the path of the fissures and, almost without exception, is more or less arcuate, not detecting a straight line cracking, knowing the fact that the tertiary dentine is deposited as a response to irritation and injury of moderate intensity.

\section{Acknowledgements}

In this article, all the authors have equal contributions to the first author.

\section{References}

1. TEODORE ROBERTSON, HARALD HEYMANN. Art and Science of Operative Dentistry, Ed Swift fifth Edition, Elsevier-Mosby 2006.

2. Glossary of endodontics terms, $8^{\text {th }}$ edn. (2012) American Association of Endodontists, Chicago.

3. ADCOCK JM, SIDOW SJ, LOONEY SW et al. (2011) Histologic evaluation of canal and isthmus debridement efficacies of two irrigant delivery techinques in a closed system. J Endodo 37: 544-348,

4. BAUMANN MA, SCHWEBEL T, KRIETE A. (1993) Dental anatomy portrayed with microscop volume investigations. Comput Med Imaging Graph, 17:221228.

5. BERGENHOLTZ G, SPANGBERG LS. (2004) Controversies in endodonctics. Crit Rev Oral Biol Med, 15:99-114.

6. ENDAL U, SHEN Y, KNUT A, GAO Y, HAAPASALO M. (2011) A high-resolution computed tomographic study of chages in root canal isthmus area by instrumentation and root filling. J Endod, 37:223-227.

7. GRANDE NM, PLOTINO G, GAMABARINI G et al. (2012) Present and future in the usa of micro-CT scanner 3D analysis for the study of dental and root canal morphology. Ann Ist Super Sanita 48:26-34.
8. HASSAN BA, PAYAM J, JUYANDA B, VAN DER STELT P, WESSENLINK PR. (2012) Influence of scan setting selections on root canal visibility with cone beam CT. Dentomaxilofac Radiol, 41:645-648.

9. INDIYATULLIN D, CORUM C, MOELLER S, PRASAD HS, GARWOOD M, NIXDORF DR. (2011) Dental magnetic resonance imaging: making the invisible visible. J Endod, 37:745-752.

10. KERES K, TRONSTAD L. (1977c) Morphometic observations on root canals of human premolars. J Endod, 3:74- \&9.

11. LU TY, YANG SF, PAI SF. (2006) Complicated root canal morphology of mandibular first premolar in a Chinese population using the cross section method. J Edod, 32:932-936.

12. ORDINOLA-ZAPATA R, BRAMANTE CM, VILLAS-BOAS MH, CAVENAGO BC, DUARTE MH, VERSIANI MA. (2013) Morphologic microcomputed tomography analysis of mandibular premorals with three root canals. J Endod, 39:11301135 .

13. PECORA JD, SOUSA-NETO MD, SAQUY PC, WOELFEL JB. (1993c) In vitro study of root canal anatomy of maxillary second premolars. Braz Dent J, 3:81-85.

14. PERLEA P, NISTOR C, GHEORGHIU I, SUCIU I., DIACONU O, TOMA C, ILIESCU ALA, ILIESCU A. Configuraţia endodontică a premolarilor unu maxilari la populaţia românească. Ro J Stomatol, 2014; 60(4):308-311.

15. PERLEA P, ILIESCU ALA, TOMA C, GHEORGHIU I, NISTOR C, SCĂRLĂTESCU S, SUCIU I, ILIESCU A. Studiu radiologic al configuraţiei endodontice la premolarii unu mandibulari la populaţia românească. Ro J Stomatol, 2014; 60(4):299-303.

16. A.L. SYMONS, C.-Y. CHU, I.A. MEYERS. The effect of fissure morphology and pretreatment of the enamel surface on penetration and adhesion of fissure sealants. J Oral Rehabil. 1996, 23; 791-798.

17. H.H.K. XU, D.T. SMITH, S. JAHANMIR. Indentation Damage and Mechanical Properties of Human Enamel and Dentin. Journal Of Dental Research, 1998. 